\title{
COMPARATIVE CHARACTERIZATION OF BASIL, MINT AND SAGE EXTRACTS
}

\author{
RAMONA BLEIZIFFER ${ }^{a}$, CORNELIA MESAROS ${ }^{b}$, \\ SONIA SUVAR ${ }^{\mathrm{a}}$, PAULA PODEA ${ }^{*}$, ANDREEA IORDACHE ${ }^{\mathrm{d}}$, \\ FLORENTINA-DIANA YUDIN ${ }^{a}$, MONICA CULEA ${ }^{a}$
}

\begin{abstract}
Aromatic plants are widely used in food preparation for aroma and fragrance, but they are also a good source of amino acids and fatty acids. Three indigenous species, Basil (Ocimum basilicum), mint (Mentha piperita) and sage (Salvia officinalis) which are traditionally used in medicine and food, were characterized and compared in terms of volatile extracts, amino acids, fatty acids contents and antioxidant activities. The gas chromatographic-mass spectrometry (GC-MS) method is a suitable technique for the characterization of the compounds of the herbs extracts. Antioxidant activity was measured using extracts ability to scavenge DPPH radicals. Linalool was found the major compound in basil, menthol in mint and a-thujone in sage. The dominant amino acids identified in the plants extracts were glutamic acid and aspartic acid in basil and mint, while proline was found in high concentration in sage and mint. The total free fatty acids (TFA) were highest in mint, followed by sage and basil. The essential omega 3 alpha-linolenic acid (ALA) was identified in all three extracts. All samples exhibited antioxidant activity, sage extract having the highest antioxidant activity.
\end{abstract}

Keywords: Ocimum basilicum, Mentha piperita, Salvia officinalis, volatile compounds, amino acids, fatty acids.

\section{INTRODUCTION}

Basil (Ocimum basilicum), mint (Mentha piperita) and sage (Salvia officinalis), belonging to the Lamiaceae family, are medicinal plants and culinary herbs due to their delicate aroma and fragrance. Basil, one of the most important

\footnotetext{
a Babeş-Bolyai University, Faculty of Physics, 1 Kogălniceanu str., 400084 Cluj-Napoca, Romania.

b University of Medicine and Pharmacy, 38 Gh. Marinescu St., Târgu Mureş, Romania.

c Babeş-Bolyai University, Faculty of Chemistry and Chemical Engineering, 1 Kogălniceanu str., 400084 Cluj-Napoca, Romania.

d National R\&D Institute for Cryogenics and Isotopic Technologies, 4 Uzinei str., 240050 Râmnicu Vâlcea, Romania.

*Corresponding author: mpaula@chem.ubbcluj.ro
} 
and wildly used spices, has been shown to have antioxidant, antibacterial, and anti-diarrheal activities [1]. Mint (Mentha piperita) has anti-inflammatory, cytotoxic and antioxidant activities [2]. Sage (Salvia officinalis) has a savory, peppery flavor and is used as condiment. Sage's studies in healthy humans have demonstrated improved memory, attention/executive function, alertness and mood, improved cognitive functioning and behavioral function [3-5]. It can be used also in treating digestive disorders such as poor digestion and bloating.

Herbs are often used in our food as condiments, tea or in pharmaceutical extracts. Most of these herbs are investigated for their nutritional and pharmaceutical properties. The optimization of micronutrients in our food is very important. Amino acids play an important role in human nutrition. The level of essential amino acids dictates food nutritive value. The free amino acids have an important effect in food flavor, influence its palatability, and contribute to the formation of amines and volatile compounds. Omega- 3 fatty acids supplementations in humans have beneficial effects on subjective global assessment score and metabolic profiles. Amino acids, fatty acids and qualitative chemical composition of herbs may be influenced by environmental and geographical conditions.

The aim of investigations was to determine the differences between three herbs purchased from Romania with respect of the essential amino acids and fatty acids present in this herbs often used as tea or condiments. Also their volatile compounds and antioxidant activity were compared.

For the characterization of the compounds in herbs extracts, gas chromatography-mass spectrometry (GC-MS) analysis is a suitable technique. Amino acids and fatty acids were first derivatizated to obtain trifluoroacetyl ester derivatives in the case of amino acids [6-11] and fatty acids methyl esters (FAMEs) for free fatty acids [12-17]. Antioxidant activities of extracts were also compared.

\section{RESULTS AND DISCUSSION}

In the present work we have evaluated and compared the chemical composition of volatiles, amino acids and fatty acids contents in three herbs species: basil, mint and sage. For compounds characterization of herbs extracts, different approaches involving extraction methods, purification by ion exchange technique in the case of amino acids, derivatization steps and gas chromatography-mass spectrometry (GC-MS) analysis were applied.

For the amino acids and fatty acids analysis, the methods were validated injecting standard solutions of amino acids and fatty acids respectively. Samples are following the same derivatization procedure as standards. Good values for linearity, precision, accuracy and limit of detection were obtained [6]. 
The quantitative method gave a good linearity regression curve, obtained with standards with known concentration of each amino acid, in the range $0-100 \mu \mathrm{g} \times \mathrm{mL}^{-1}$ and by adding the same quantity of internal standard $\left(50 \mu \mathrm{g} \times \mathrm{mL}^{-1}\right)$. The internal standard, ${ }^{15} \mathrm{~N}$-glycine, $\left(99\right.$ atom $\left.\%{ }^{15} \mathrm{~N}\right)$ and glycine required correction by deconvolution and matrix calculation. Fractional isotopic abundances for natural glycine and isotopomer were obtained experimentally $[8,9]$ (Table 1).

Table 1. The matrix design (left) and the pseudoinverse matrix (right) used for glycine calculation [6]

\begin{tabular}{cccccc}
\hline Glycine & {$[\mathbf{M}]$} & {$[\mathbf{M + 1}]$} & Glycine & {$[\mathbf{M}]$} & {$[\mathbf{M + 1}]$} \\
\hline n.a. & 0.95 & 0.05 & n.a. & 1.05 & -0.05 \\
${ }^{15} \mathrm{~N}$ & 0.01 & 0.99 & ${ }^{15} \mathrm{~N}$ & -0.01 & 1.01 \\
\hline
\end{tabular}

Glycine was calculated by matrix and regression curve calculation. Precision and accuracy for glycine, measured for standards of 20 and 30 $\mu \mathrm{g} \times \mathrm{mL}^{-1}(\mathrm{n}=7)$, showed very good results, lower than $6 \%$ and respectively $11 \%$.

Method validation, using amino acid standards following the extraction and derivatization procedure $(n=3)$, gave good results. The regression curves for each aminoacid standard were studied between of 0 and $150 \mathrm{mg} \times \mathrm{mL}^{-1}$, and the same quantity of internal standard was added. Good linearity results for amino acids were found, the regression coefficient over 0.99 for Ala, Gly,Thr, Ser, Leu, Ile, Pro, Orn and higher than 0.97 for the other standards. The precision and accuracy were lower than $20 \%$, for standards

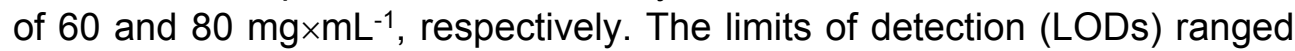
from $10^{-3}$ for alanine, glycine, ornithine, and leucine to $10^{-2} \mathrm{mg} \mathrm{mL}^{-1}$.

The volatile extracts of basil gave as major compounds: linalool (26.13\%), estragole (21.16\%), caryophyllene $(10.13 \%)$ and limonene $(8.18 \%)$. Sage gave as major compounds: $\alpha$-thujone $(25.08 \%)$, camphor $(20.46 \%)$, eucalyptol (13.85\%) and $\beta$-thujone (13.37\%) (Fig.1). In mint, the major compounds were menthol (37.7\%), isomenthone (15.97\%), eucalyptol $(5.44 \%)$ and menthofuran (4.8\%) (Fig. 2). 
R. BLEIZIFFER, C. MESAROS, S. SUVAR, P. PODEA, A. IORDACHE, F.-D. YUDIN, M. CULEA

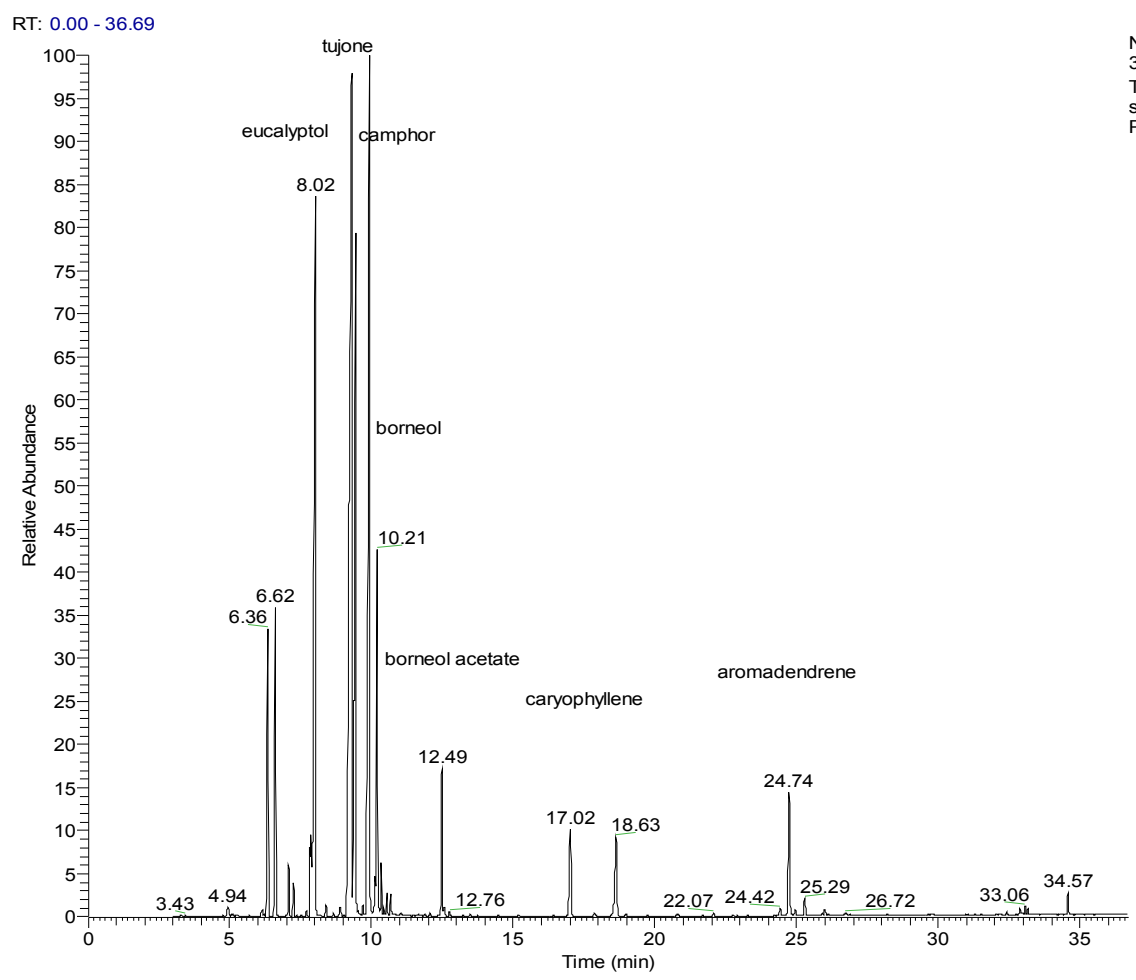

Figure 1. Identification of sage volatiles separated on a Rtx-5MS capillary column

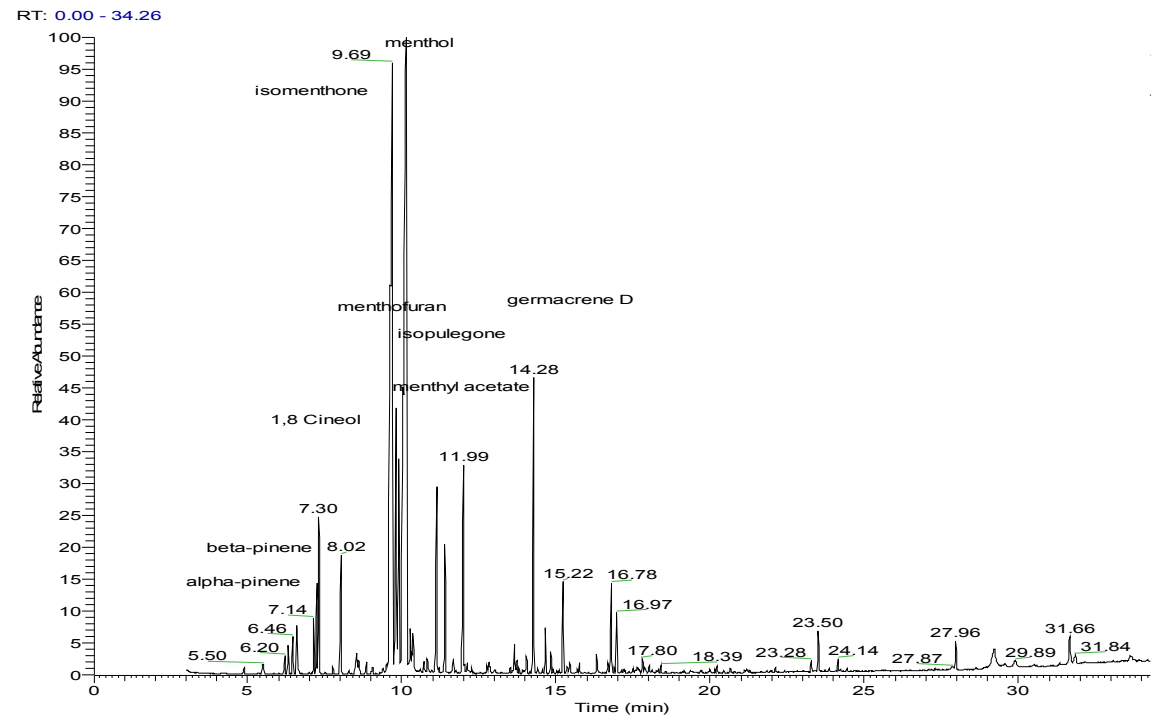

Figure 2. The chromatogram of volatiles identified in mint extract 


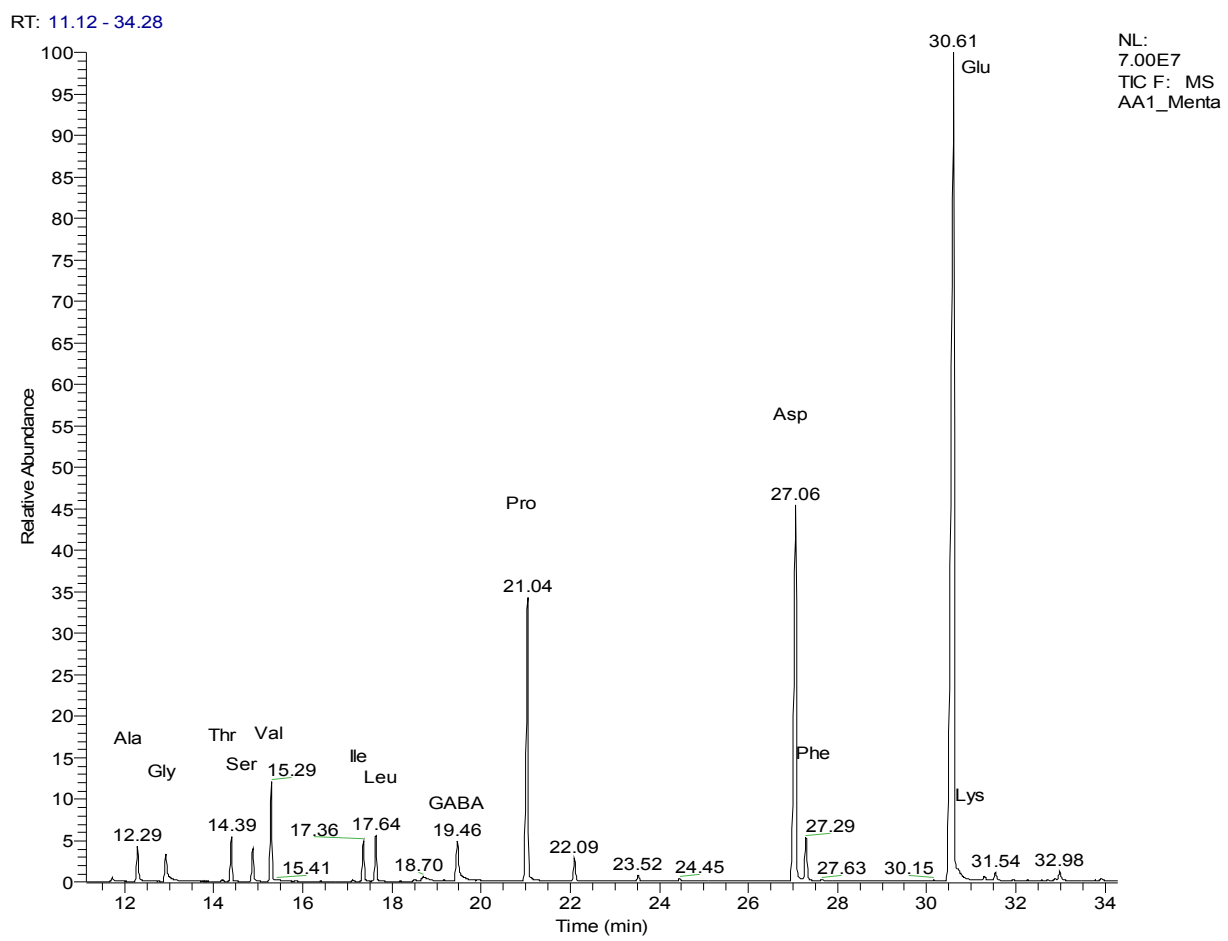

Figure 3. GC-MS separation and identification of amino acids present in mint extract

Fig. 3 presents the total ion chromatogram (TIC) of amino acids separated and identified in mint extract. NIST library was used for compounds identification. The elution order was: alanine (Ala), glycine (Gly), threonine (Thr), serine (Ser), valine (Val), leucine (Leu), isoleucine (lle), $y$-aminobutiric acid (GABA), proline (Pro), methionine (Met), aspartic acid (Asp), phenylalanine (Phe), ornitine (Orn), glutamic acid (Glu), lysine (Lys), tyrosine (Tyr).

The dominant amino acids identified were glutamic acid and aspartic acid in basil and mint and proline content was higher in sage and mint. We found that in sage, proline, glutamic acid, gama-aminobutiric acid, alanine, valine and glycine were important quantitatively. The highest free total amino acids were observed in mint and sage, over $1 \mathrm{mg} \cdot \mathrm{g}^{-1}$ (Fig.4). Fig. 5 presents the ratio EAA/TAA (essential amino acids/total amino acids) which is higher in basil, followed by mint and sage. The highest concentration of essential amino acids were found in mint $\left(1.07 \mathrm{mg}^{-1} \mathrm{~g}^{-1}\right)$, followed by sage $\left(0.33 \mathrm{mg} \cdot \mathrm{g}^{-1}\right)$ and basil $\left(0.1 \mathrm{mg}^{-1} \mathrm{~g}^{-1}\right.$ (Table 2, Fig. 6).

Analyzing the fatty acids content in these three herbs, essential omega 3 alpha-linolenic acid (ALA) were identified and the highest content was found in basil, followed by sage and mint. Also, the total free fatty acids 
(TFA) content was determined in basil $\left(72.8 \mathrm{mg} \cdot \mathrm{g}^{-1}\right)$, mint $\left(13.3 \mathrm{mg} \cdot \mathrm{g}^{-1}\right)$ and sage $\left(98.8 \mathrm{mg}^{-1}\right)$. The unsaturated fatty acids (UFA) and polyunsaturated fatty acids (PUFA) were analyzed, the content been higher in sage and basil in comparison with mint. The ratio UFA/SFA was higher in basil and mint, followed by sage (Table 3, Fig. 8 ).

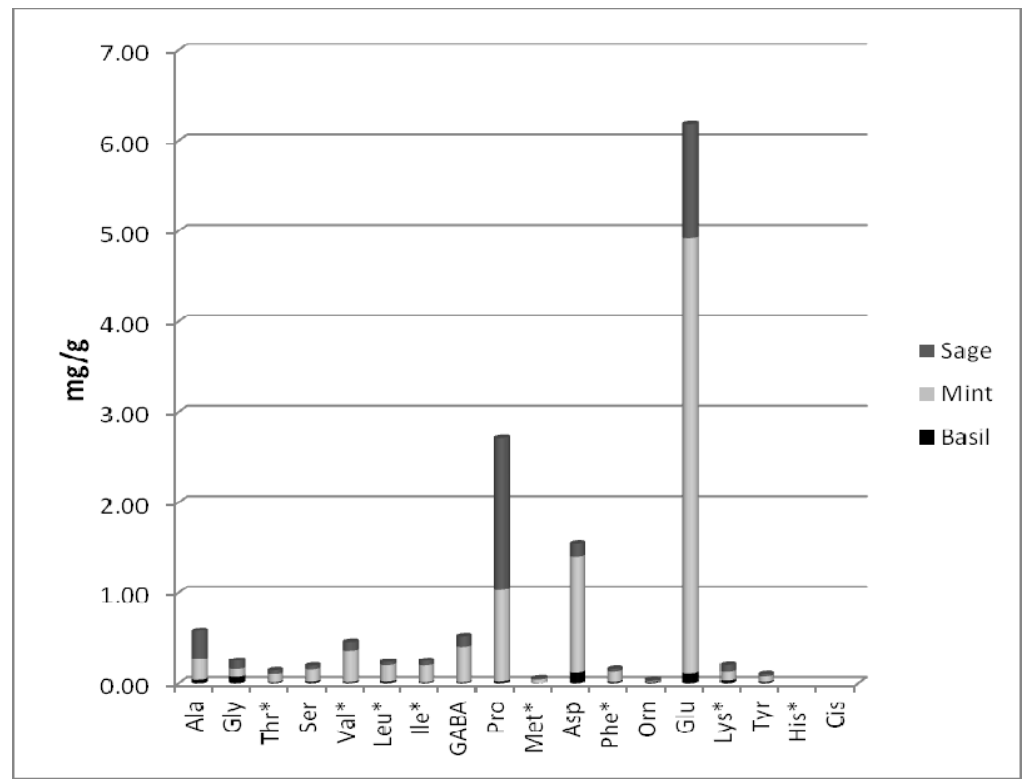

Figure 4. Free amino acids comparison in basil, sage and mint extracts $\left(\mathrm{mg}^{-1} \mathrm{~g}^{-1}\right)$

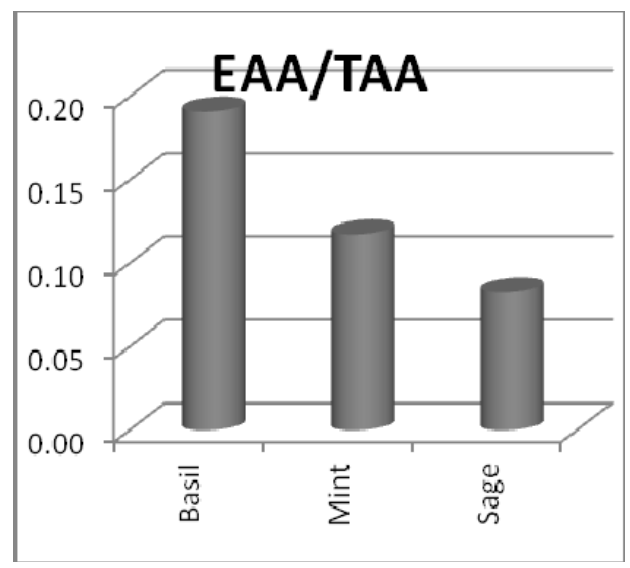

Figure 5. Free amino acids comparison in basil, sage and mint extracts $\left(\mathrm{mg}^{-\mathrm{g}^{-1}}\right)$ 
COMPARATIVE CHARACTERIZATION OF BASIL, MINT AND SAGE EXTRACTS

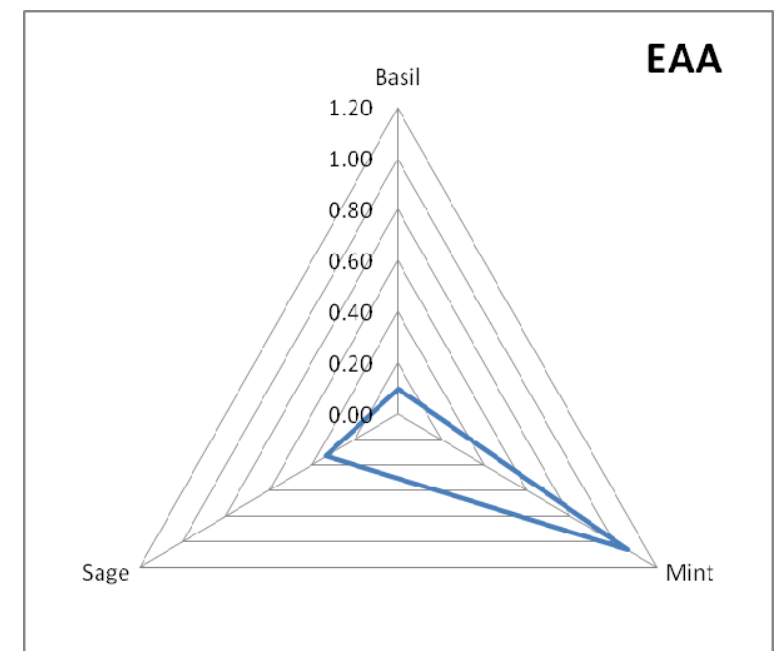

Figure 6. Comparison of essential amino acids in the three herbs extracts $\left(\mathrm{mg} \cdot \mathrm{g}^{-1}\right)$

Table 2. Amino acids values, in $\mathrm{mg} \cdot \mathrm{g}^{-1}$, in the analyzed herbs

\begin{tabular}{|l|c|c|c|}
\hline AA/Herbs & Basil & Mint & Sage \\
\hline Ala & 0.04 & 0.22 & 0.32 \\
\hline Gly & 0.07 & 0.09 & 0.09 \\
\hline Thr $^{*}$ & 0.01 & 0.09 & 0.04 \\
\hline Ser & 0.02 & 0.14 & 0.04 \\
\hline Val $^{*}$ & 0.01 & 0.34 & 0.10 \\
\hline Leu $^{*}$ & 0.02 & 0.18 & 0.04 \\
\hline lle $^{*}$ & 0.01 & 0.19 & 0.05 \\
\hline GABA & 0.01 & 0.38 & 0.12 \\
\hline Pro $_{\text {Met }^{*}}$ & 0.02 & 1.01 & 1.68 \\
\hline Asp & 0.00 & 0.04 & 0.01 \\
\hline Phe & 0.12 & 1.28 & 0.15 \\
\hline Orn & 0.01 & 0.12 & 0.03 \\
\hline Glu & 0.01 & 0.01 & 0.01 \\
\hline Lys & 0.11 & 4.81 & 1.26 \\
\hline Tyr & 0.03 & 0.10 & 0.07 \\
\hline TAA & 0.02 & 0.06 & 0.04 \\
\hline EAA & 0.51 & 9.07 & 4.03 \\
\hline EAA/TAA & 0.10 & 1.07 & 0.33 \\
\hline
\end{tabular}


R. BLEIZIFFER, C. MESAROS, S. SUVAR, P. PODEA, A. IORDACHE, F.-D. YUDIN, M. CULEA

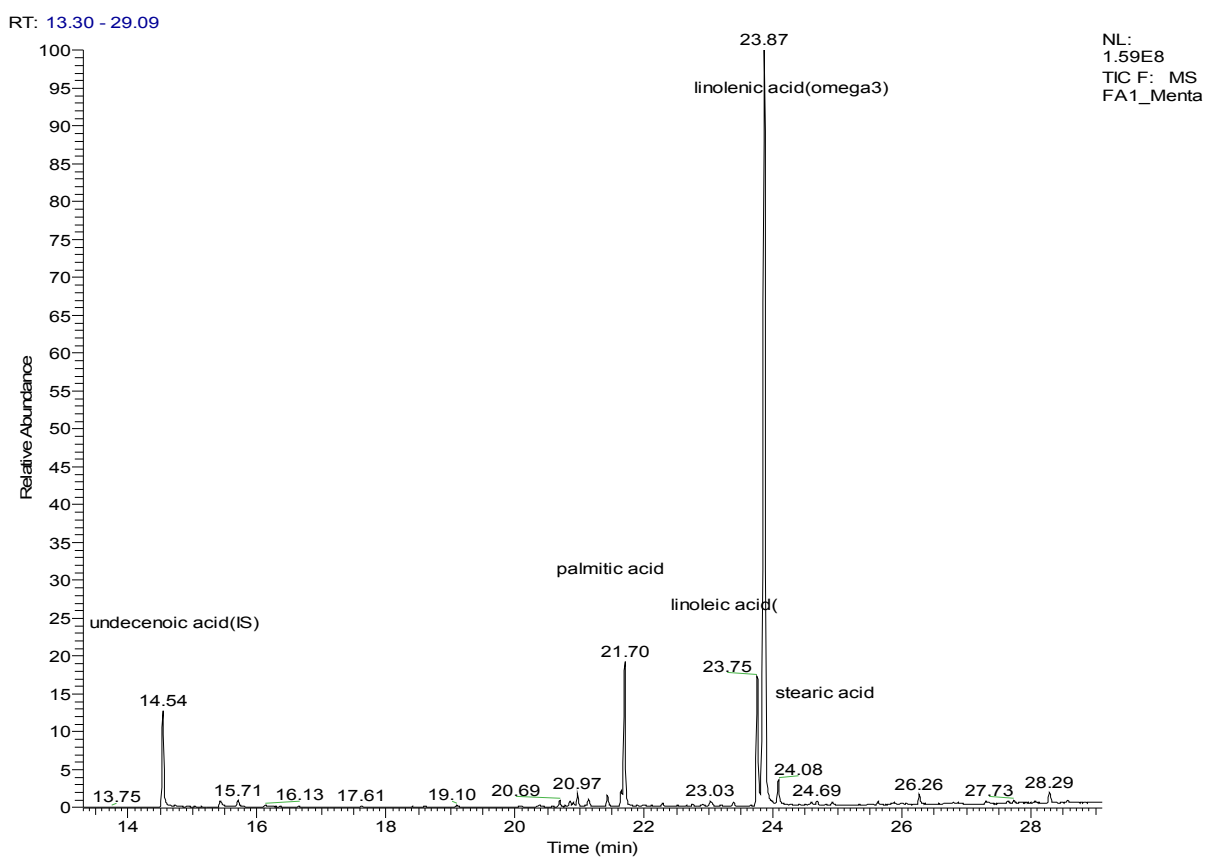

Figure 7. GC-MS separation and identification of fatty acids in mint extract

The identified fatty acids separated as FAMEs in the mint extract is presented in Fig.7. The omega-3 linolenic acid was the highest concentrated fatty acid determined in each herb extract.
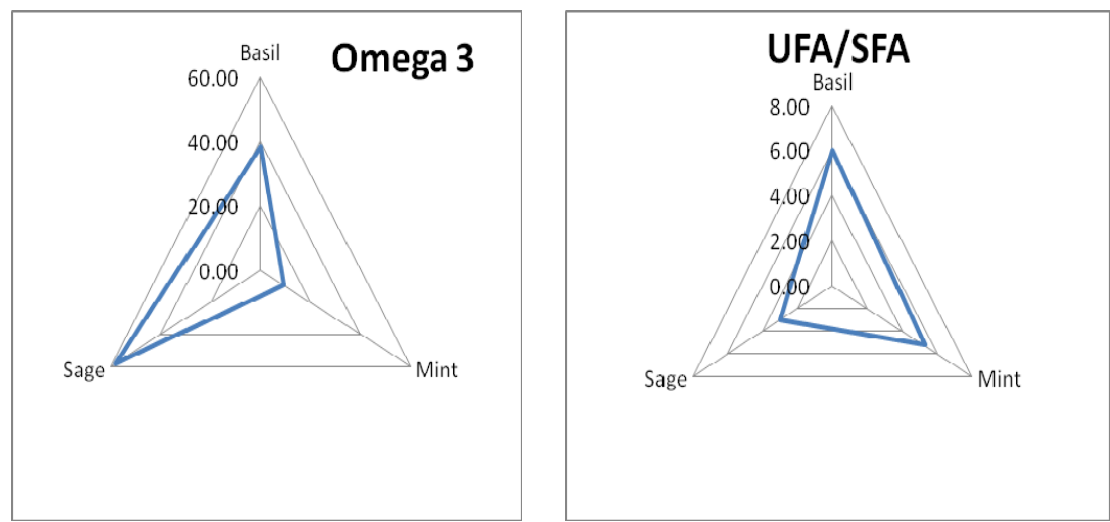

Figure 8. Linolenic acid and UFA/SFA ratio comparison in the herbs studied 
Table 3. Free fatty acids $(\mathrm{FA})$ values, in $\mathrm{mg} \cdot \mathrm{g}^{-1}$, in the analyzed herbs

\begin{tabular}{|l|c|c|c|}
\hline FA & Basil & Mint & Sage \\
\hline C16:1 & 0.12 & 0.18 & 0.60 \\
\hline C16:0 & 7.12 & 1.44 & 13.65 \\
\hline C18:2 & 23.89 & 1.44 & 15.36 \\
\hline C18:3 & 38.39 & 9.55 & 58.11 \\
\hline C18:0 & 2.66 & 0.37 & 3.54 \\
\hline C20:0 & 0.26 & 0.13 & 4.33 \\
\hline C22:0 & 0.13 & 0.13 & 1.81 \\
\hline C24:0 & 0.18 & 0.04 & 1.38 \\
\hline omega6/omega3 & 0.62 & 0.15 & 0.26 \\
\hline MUFA & 0.12 & 0.18 & 0.60 \\
\hline UFA & 62.41 & 11.18 & 74.06 \\
\hline SFA & 10.35 & 2.11 & 24.70 \\
\hline PUFA & 62.28 & 11.00 & 73.46 \\
\hline UFA/SFA & 6,03 & 5,30 & 3,00 \\
\hline TFA & 72,76 & 13,29 & 98,76 \\
\hline
\end{tabular}

Antioxidant activity was determined using DPPH scavenging activity. All three herbs ethanolic extracts showed an antioxidant activity. Sage and mint extracts proved to have a very high antioxidant potential, while basil showed a moderate antioxidant potential. The half maximal effective concentration $\left(E C_{50}\right)$ for each type of extract was determined. The most antioxidant extact was sage extract $\left(E C_{50}=8.22 \mu \mathrm{g}^{*} \mathrm{~mL}^{-1}\right)$, followed by mint extract $\mathrm{EC}_{50}=13.65 \mu \mathrm{g}^{*} \mathrm{~mL}^{-1}$, and basil extract $\mathrm{EC}_{50}=112.58 \mu \mathrm{g}^{*} \mathrm{~mL}^{-1}$. The procentage of $\mathrm{DPPH}$ scaveging activity at $50 \mathrm{\mu g}^{*} \mathrm{~mL}^{-1}$ of each plant extract, after 30 minutes was determined and the highest value was obtained in sage extract $(92.26 \%)$ followed by mint extract $(88.66 \%)$ and basil extract $(24.28 \%)$.

Comparing the DPPH scavenging activity of these three plants extracts with plants extracts from other geographical sources, showed that we have obtained similar results. Our sage extract (92.26\%), from Târgu Mures area, proved to have comparable DPPH scavenging activity with other sage extracts from different Romanian sources (85.12\%) [18], but higher then methanolic extract from Tunisia. $\left(E_{50}=29.33 \mu \mathrm{g}^{*} \mathrm{~mL}^{-1}\right)$ [19]. Mentha piperita, from Târgu Mures $\left(E_{50}=13.65 \mu^{*} \mathrm{~mL}^{-1}\right)$ area, exhibits a lightly higher activity then Mentha piperita from Northeastern Algeria $\left(E_{50}=17.00 \mu g^{*} \mathrm{~mL}^{-1}\right)$ [20], while DPPH scavenging activity of our mint ethanolic extracts $(88.66 \%)$ showed higher activity than diethylether mint extract from Saudi Arabia (34.21\%) [21]. 
The EC $50 \%$ of our Ocimum basilicum etahnolic extract (EC50 $\left.=112.58 \mu \mathrm{g}^{*} \mathrm{~mL}^{-1}\right)$ showed comparable activity with other ethanolic basil extract from different Romanian sources $\left(E_{50}=124.95 \mu^{*} \mathrm{~mL}^{-1}\right)$ [22], while aqueous basil extract from Serbia $\left(E_{50}=17.93 \mu \mathrm{g}^{*} \mathrm{~mL}^{-1}\right)$ showed a powerful scavenging activity [23].

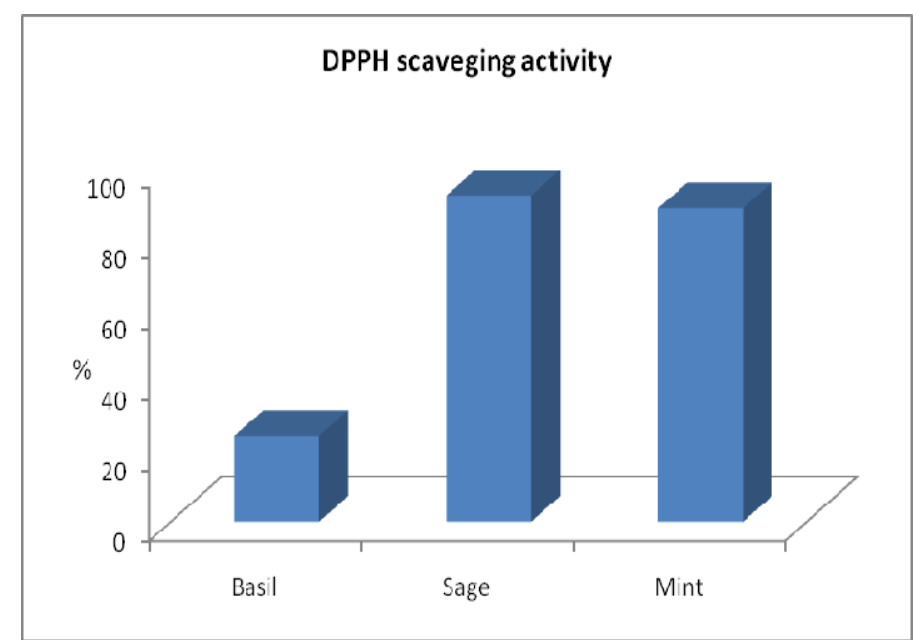

Figure 9. DPPH scavenging activity of ethanolic herbs extracts $\left(50 \mu \mathrm{g}^{*} \mathrm{~mL}^{-1}\right)$

\section{CONCLUSIONS}

The GC-MS is a suitable technique for the characterization of the compounds of the herbs extracts. The validation parameters: linearity, correlation coefficients, precision, accuracy, in the range of interest, were good. Isotopic dilution by using a labeled internal standard increased precision and avoids the overlapping of analyzed compounds. The methods are useful for nutrient and diet control. The compounds identified in the herbs studied are characteristic for the odour or aroma of these plants.

The highest free total amino acids were observed in mint and sage $\left(>4 \mathrm{mg} \cdot \mathrm{g}^{-1}\right)$. Proline was higher in sage and mint. The presence of omega 3 fatty acid is very important for healthy and the highest quantity was found in sage, followed by basil and mint. Sage and mint extract proved to have a high and comparable antioxidant activity, while basil extract have a moderate antioxidant activity. 


\section{EXPERIMENTAL SECTION}

\section{Materials and methods}

Plants, basil (Ocimum basilicum), mint (Mentha piperita) and sage (Salvia officinalis), were purchased from Botanical Garden of Târgu Mures, Transylvania, Romania. All reactive and standards were purchased from Merck (Darmstadt, Germany).

\section{GC-MS apparatus}

A DSQ Thermo Finnigan Proanalysis, Bucharest, Romania quadrupole mass spectrometer coupled with a Trace GC was used. Gas chromatography was performed on a $5 \%$ phenyl methylpolysiloxane Rtx$5 \mathrm{MS}$ capillary column, $30 \mathrm{~m} \times 0.25 \mathrm{~mm}, 0.25 \mu \mathrm{m}$ film thickness in a suitable temperature program. In the case of amino acids separation the program was: from $70{ }^{\circ} \mathrm{C}, 2 \mathrm{~min}, 5^{\circ} \mathrm{C} / \mathrm{min}$ to $110^{\circ} \mathrm{C}, 10^{\circ} \mathrm{C} / \mathrm{min}$ to $290^{\circ} \mathrm{C}, 16^{\circ} \mathrm{C} / \mathrm{min}$ to $300^{\circ} \mathrm{C}$. [1]. The temperature program for FAMEs and volatiles separation was: $50^{\circ} \mathrm{C}$ for 2 min rising with a rate of $8^{\circ} \mathrm{C} / \mathrm{min}$ at $310^{\circ} \mathrm{C}(8$ minutes). Helium was used as carrier gas at a flow rate of $1 \mathrm{~mL} / \mathrm{min}$. $1 \mu \mathrm{L}$ of each sample was injected into the GC-MS using the split mode (10:1) using a TriPlus autosampler (Proanalysis, Bucharest, Romania). The mass spectrometer was operated in El mode at $70 \mathrm{eV}$, emission current was $100 \mu \mathrm{A}$ and mass spectra mass range 50-500 a.m.u. Transfer line temperature was set at $250^{\circ} \mathrm{C}$, injector at $250^{\circ} \mathrm{C}$ and ion source at $250^{\circ} \mathrm{C}$. Antioxidant activity was determined using a Varian Cary 50 Spectrophotometer.

\section{Extraction procedures}

For extraction and derivatization of amino acids, $100 \mathrm{mg}$ of crushed leaves were extracted with $1 \mathrm{ml}$ of $6 \%$ trichloroacetic acid in a ultrasound bath for $5 \mathrm{~min}$. The mixture was centrifuged for $5 \mathrm{~min}$ at $6000 \mathrm{rpm}$ and supernatant was collected for purification. $0.5 \mathrm{ml}$ of the supernatant and $50 \mu \mathrm{g}$ $\left[{ }^{15} \mathrm{~N}\right]$-glycine (internal standard) was passed through a Dowex 50W-W8 exchange resin, $4 \times 40 \mathrm{~mm}$ column (activated). The collected solution was dried in a nitrogen flow at $60^{\circ} \mathrm{C}$ or by using a vacuum centrifuge at $60^{\circ} \mathrm{C}$. The derivatization method included an esterification of the carboxylic function using $200 \mu \mathrm{l}$ butanol : acetyl chloride $(4: 1 \mathrm{v} / \mathrm{v})$, for $1 \mathrm{~h}$ at $110^{\circ} \mathrm{C}$, followed by an acetylation of the amine function using $100 \mu$ trifluoroacetic anhydride, for $20 \mathrm{~min}$ at $80^{\circ} \mathrm{C}$. 
For extraction and derivatization of fatty acids, $100 \mathrm{mg}$ of crushed leaves was sonicated with $0.6 \mathrm{ml}$ water $/ \mathrm{NaCl}$ and $0.8 \mathrm{ml}$ methanol for $1 \mathrm{~min}$, then mixed with $0.8 \mathrm{ml}$ chloroform and $3 \mathrm{~min}$ centrifuged $(5800 \mathrm{rot} / \mathrm{min})$; the lower layer was collected and extraction was repeated with $0.4 \mathrm{ml}$ chloroform. The lower chloroform phase containing the extracted fatty acids was then dried in a nitrogen flow, at $60^{\circ} \mathrm{C}$.

The lipids were converted to corresponding FAMEs by esterification of the carboxylic functions with $200 \mu \mathrm{L}$ methanol: acetyl chloride $4: 1$ (v:v), 20 $\min , 80^{\circ} \mathrm{C}$. The derivatives were evaporated to dryness by a nitrogen stream, at $60^{\circ} \mathrm{C}$, and then dissolved in $500 \mu \mathrm{L}$ dichloromethane. $10 \mu \mathrm{g}$ of $\mathrm{C} 11: 1$ was added to each sample for GC-MS quantitation.

For extraction of volatiles, $100 \mathrm{mg}$ of crushed leaves were ultrasounded and extracted with $1 \mathrm{~mL}$ ethanol at $60^{\circ} \mathrm{C}$ for 15 minutes. The mixture was centrifuged at $5800 \mathrm{rpm}$ and the supernatant collected filtred and injected in the GC/MS and tested for antioxidant activity.

For determination of antioxidant activity, DPPH antioxidant assay was used. A solution of $40 \mu \mathrm{M} 2,2$-diphenyl-1-picrylhydrazil (DPPH•) in ethanol was decolorize using different concentration of each plant extract. The monitoring of DPPH reduction was followed at $517 \mathrm{~nm}$. The percentage of DPPH scavenging activity is expressed using following formula: $\mathrm{DPPH}_{\text {inhibition } \%=}$ $\left[\left(A_{i}-A_{t}\right) / A_{i}\right] \times 100$. For determination of effective concentration $\left(E C_{50}\right)$, different concentration of each plant extract $5 \mu \mathrm{g} / \mathrm{mL}, 10 \mu \mathrm{g} / \mathrm{mL}, 20 \mu \mathrm{g} / \mathrm{mL}, 50 \mu \mathrm{g} / \mathrm{mL}$, $100 \mu \mathrm{g} / \mathrm{mL}$ were used. The $\mathrm{EC}_{50}$ was determined by plotting the $\mathrm{DPPH}_{\text {inhibition }} \%$ against used extract concentration.

\section{REFERENCES}

1. Y. Lu, B. Gao, P. Chen, D. Charles, L. Yu, Food Chemistry, 2014, 154, 262.

2. Z. Sun, H. Wang, J. Wang, L. Zhou, P. Yang, PLOS ONE, 2014, 9(12): e114767.

3. D.O. Kennedy, E. L. Wightman, Advances in Nutrition: An International Review Journal, 2011, 2, 32.

4. S. Akhondzadeh, M. Noroozian, M. Mohammadi, S. Ohadinia, A.H. Jamshidi, M. Khani, Journal of Clinical Pharmacy and Therapeutics, 2003, 28, 53.

5. S. Vogl, P. Picker, J.Mihaly-Bison et al., Journal of Ethnopharmacology, 2013, 149, 750.

6. M. Culea, E. Horj, A. lordache, O. Cozar, Asian Journal of Chemistry, 2011, 23, 4279.

7. C. Mesaros, M. Culea, A. Iordache, O. Cozar, Bulletin UASVM Agriculture, 2009, 66, 111.

8. J. I. Brauman, "Spectral Analysis: Methods and Techniques", Ed. by J. A. Backburn, Marcel Dekker, New York, 1970. 
9. M. Culea and D.L. Hachey, Rapid Communication in Mass Spectrometry, 1995, 9, 655.

10. T. Hodisan, M. Culea, C. Cimpoiu, A. Cot, Journal of Pharmaceutical and Biomedical Analysis, 1998, 18, 319.

11. M. Culea, S. Scrob, S. Suvar, P. Podea, I. Has, S. Muste, Analytical Letters, 2015, 48, 37.

12. D. Cocan, E. Horj, M. Culea, V. Miresan, A. Pintea, Bulletin of USAMV, Cluj-Napoca, Agriculture, 2010, 67, 132.

13. A. lordache, M. Culea, E. Horj, O. Cozar, Romanian Journal of Physics, 2011, 56, 7$8,963$.

14. A. Pintea, A. Varga, P. Stepnowski, C. Socaciu, M. Culea, H.A. Diehl, Phytochemical Anaysis, 2005, 16, 188.

15. M. D. Huynh, D. D. Kitts, Food Chemistry, 2009, 114, 912.

16. U. Chukwuemeka, G. I. Ndukwe, T. O. Audu, Internet Journal of Food Safety, 2008, $10,9$.

17. N. M. Arat, I. H. Haliloğlu, Ö. Ayik, Turkish Journal of Veterinary and Animal Sciences, 2003, 27, 311.

18. A. V. Pop, M. Tofană, S. A. Socaci, D. Vârban, M. Nagy, Maria-D.Borş, S. Sfechiş, Bulletin UASVM Food Science and Technology, 2015, 72, 210.

19. I. Hamrouni-Sellami, F.Z. Rahali, I.B. Rebey et al., Food Bioprocess Technology, 2013, 6, 806.

20. A. Benabdallah, C. Rahmoune, M. Boumendjel, O. Aissi, C. Messaoud, Asian Pacific Journal of Tropical Biomedicine, 2016, 6(9), 760-766.

21. F. Al-Juhaimi, K. Ghafoor, Pakistan Journal of Botany, 2011, 43(4), 2235.

22. L. Vlase, D. Benedec, D. Hanganu, G. Damian, I. Csillag, B. Sevastre, A. Mot, R. Silaghi-Dumitrescu, I. Tilea, Molecules, 2014, 19, 5490-5507.

23. B. Kaurinovic, M. Popovic, S. Vlaisaljevic, S. Trivic, Molecules, 2011, 16, 7401-7414. 